Good medical practice

\section{Good medical practice for occupational physicians}

\section{Koh, S-M Lee}

\section{Standards that are expected of doctors engaged in occupational medicine practice}

- A complaint has been lodged against an occupational physician, claiming pro-management bias and substandard care. How should he/she be judged for professional accountability? Indeed, what are the useful benchmarks to apply for performance appraisal?

- A worker who is stressed at work exhibits early signs of depression. Should informing the managers and supervisors be a necessary part of the remedial plan, so that investigations can be made into work practices and procedures that may be the stressors?

- A member of the occupational health team has a health related personal problem that is affecting the work performance of the whole team. As a physician and team leader, how should the occupational physician manage that person and the team?

S ociety demands the highest standards of professional competence and ethical conduct from doctors. The working population expects no less, and insists on equally high standards of proficiency in care and conduct from occupational physicians. However, defining what exactly constitutes good medical practice and acceptable standards of professional competence and conduct is not so easily done. For example, how can the questions posed in the above scenarios be answered? Yet answers and guidance are needed, not only for the public, workers, and employers, but also for occupational physicians. The Faculty of Occupational Medicine (FOM) has prepared a publication, Good Medical Practice for Occupational Physicians, ${ }^{1}$ which attempts to provide some answers to these questions, and act as a guide for occupational physicians.

In essence, this publication offers a specialty specific interpretation of the UK General Medical Council (GMC) document entitled Good Medical Practice. ${ }^{2}$ But why the need for a specialty specific interpretation? In occupational medical practice, patient consultations may often be in the form of routine medical examinations. These examinations are often conducted because of statutory requirements or at the request of the employer. In addition, besides his obligations to the patient, occupational physicians also have a duty to the community of fellow workers as a group, as well as to the employer of the patient. The obligations to these three parties-the patient, the fellow workers, and the employer-are linked to one another. For instance, the occupational physician who diagnoses and manages a work related illness will automatically assess and re-evaluate the risk for the community of other fellow workers who are similarly exposed and therefore may be potential cases waiting to happen. The employer and management have to be involved in the control of risk, as it is their duty, and also in their interest, to provide a safe and healthy work environment.

Given the unique features of occupational health practice, the GMC guidelines on Good Medical Practice need to be applied within this specialty specific context if they are to be helpful. Thus the Faculty's provision of "detailed, explicit statements about good occupational health practice, set out in words similar to those used by the GMC", is a welcome guide for practising occupational physicians, who should already be aware of the GMC guide.

The focus of the document is on clinical obligations to patients, rather than professional and managerial obligations to employers and third parties. Thus, for use in performance appraisal of occupational physicians, appraisers should be aware of this focus of the document on clinical obligations to patients, and be aware that the scope of occupational health work extends beyond this narrow area.

Good Medical Practice for Occupational Physicians outlines the standards that are expected of doctors engaged in occupational medicine practice. It provides guidance on a comprehensive range of activities, including:
- Providing and maintaining good standards of occupational medical care

- Teaching, training, assessing, and appraising

- Relationships with patients (consent, confidentiality, and good communication)

- Working in teams and leading them

- Dealing with complaints and conduct issues

- Probity (in activities such as advertising services, writing reports, conducting research, and commercial dealings)

- Health problems that may put patients at risk.

As a caveat, the document states "because there is a great deal of variation between occupational physicians in the content of their work, the relevance of each guideline to their personal practice may vary. We recommend that account be taken of this ..." It also notes that additional guidance is provided by another Faculty document, Guidance on Ethics for Occupational Physicians ${ }^{3}$ for several situations such as pre-employment assessments, medical assessments relating to sickness absence, drug and alcohol screening, biological monitoring, and business ethics. Reference is also made to other useful GMC publications such as Maintaining Good Medical Practice and Management in Health Care-the Role of Doctors.

The guide was produced following extensive consultation

According to the Faculty, the guide was produced "following extensive consultation with British occupational health specialists, the Faculty's own Ethics Committee and the GMC, and was informed by comments from several other bodies such as the Chartered Institute of Personnel and Development, the Trades Union Congress, the Health and Safety Executive, the Patient and Carers' Committee of the Royal College of Physicians and Patient Concern". These consultations strengthen the credibility of the guide, and would increase its acceptance and application in occupational health practice situations. However, since this document has been drafted in the context of a UK based setting, some portions of the guidelines may not be entirely applicable in other parts of the world.

For example, the guide advises that wherever possible, a doctor should avoid acting both as an occupational adviser as well as a primary health care physician. Multinational companies, especially those with operations in developing countries, might face some difficulty in 
adhering to this guidance. In fact, one might argue that functioning in a primary care capacity often provides a bridge though which the relationship of the occupational physician with the workforce can be strengthened. By providing clinical care and through patient contact, the occupational physician is in a better position to appreciate work related problems, work exposures, and the organisational climate. Underreporting of occupational disease is unfortunately, all too common. The occupational physician is in a much better position to diagnose occupational illnesses and work related illnesses compared to a doctor working outside the company. Cost pressures continue to be a threat to occupational health practice. For many employers, especially those with small and medium sized businesses in developing countries, primary health care remains the raison d'être of having an occupational health physician. For many occupational physicians, this route may be the only conduit through which additional occupational health care can be channelled and facilitated.

Guides drafted by international professional organisations, such as those prepared by the International Commission on Occupational Health, exist-but membership of such organisations is open to all occupational health professionals and not exclusively to physicians. Thus, the guides that have been prepared are not specific for occupational physicians, but are applicable to a wider audience, for example, ethics for occupational health professionals. ${ }^{4}$ Generally, guidance documents for good practice that originate from professional bodies face similar considerations in terms of what they should cover and whether they serve to protect the public or the profession.

The issue of confidentiality, which is mentioned in the section on Relationships with patients, is also discussed in the Guidance on Ethics. ${ }^{3}$ We have to look at this issue critically and ask for whose benefit the clause of confidentiality serves. Consent should always be sought, and at times, sought aggressively. While confidentiality should serve the patients' interest, in occupational health practice, there might be instances where releasing information to the employers may actually serve the patient's interest. Take the case of a worker with excessive exposure, or the worker with mental stress at work. How is corrective action to be taken if the supervisors and managers are not involved? In fact, informing management might be a necessary part of the remedial plan, so that they can investigate to ascertain the extent of the problem, and modify work practice, procedures, and other factors.

However, these considerations do not detract from the undoubted value of this landmark publication. In view of recent developments towards appraisals of doctors' competence, the requirements for professional revalidation, and the occurrence of situations such as those listed above, this publication by the Faculty of Medicine is to be welcomed as a set of core statements that outline standards of medical practice expected of occupational physicians.

\section{Continuous improvements should be strived for}

While the guidelines certainly bring us a step forward in the right direction, continuous improvements should be strived for. Disseminating the guidelines widely, gathering further feedback and consensus from colleagues practising occupational health in the myriad of different settings (including those who may not necessarily be occupational physicians), and considering views from all other concerned parties may result in future revisions and editions of the guide. For example, comments and inputs on the GMC guide on Good Medical Practice, now in its third edition, are still being made. A recent letter ${ }^{5}$ offers the viewpoint that the portion of the guide stating "You must not refuse to treat a patient because you may be putting yourself at risk. If patients pose a risk to your health or safety, you should take reasonable steps to protect yourself before investigating their condition or providing treatment" might give a confused message that potentially puts health care workers at increased risk.

In this regard, the Faculty could consider making the guide freely available on its website, like the GMC guides (http://www.gmc-uk.org/), or the position statements available on the website of the American College of Occupational and Environmental Medicine (http:// www.acoem.org/position/position.asp), or the online publications of the Australasian Faculty of Occupational Medicine (http://www.racp.edu.au/afom/ publicat.htm).

Next, the provision of safeguards, incentives, and disincentives to encourage the application of these guides would hopefully result in these standards being widely met, so that the working population receives the highest standards of occupational health care.

The document Good Medical Practice for Occupational Physicians can be ordered from the Faculty website, http://www.facoccmed.ac.uk/ at a cost of $£ 10.00$ (for UK and Europe) and $£ 12.50$ (outside Europe).

Occup Environ Med 2003;60: 1-2

\section{Authors' affiliations}

D Koh, Professor and Head, Department of Community, Occupational, and Family Medicine, Faculty of Medicine, National University of Singapore

S-M Lee, Consultant Occupational Physician and Medical Adviser, Shell Eastern Petroleum Pte Ltd, Singapore

Correspondence to: Prof. D Koh, Professor and Head, Department of Community,

Occupational, and Family Medicine, Faculty of Medicine, National University of Singapore; cofhead@nus.edu.sg

\section{REFERENCES}

1 Faculty of Occupational Medicine. Good medical practice for occupational physicians. December 2001

2 General Medical Council. Good medical practice, 3rd edn. London: GMC, May 2001 3 Faculty of Occupational Medicine. Guidance on ethics for occupational physicians, 5th edn. 1999.

4 International Commission on Occupational Health. International code of ethics for occupational health professionals. Singapore: ICOH, 1992.

5 Henderson MJ, Holland-Elliot K. Good medical practice for occupational health. Lancet 2002;359:895. 